Bull. Egypt. Soc. Physiol. Sci. 40 (1), 46-68

\author{
Bull. of Egyp. Soc. Physiol. Sci. \\ (Official Journal of Egyptian Society for Physiological Sciences) \\ (pISSN: 1110-0842; eISSN: 2356-9514)
}

\title{
Hydrogen Sulfide Generation Protects against Renal Ischemia/Reperfusion- induced Cardiac Hypertrophy and Arrhythmia via Amelioration of Connexin- 43 Expression and Opening of $K_{\mathrm{ATP}}$ Channels
}

\author{
Adel Mohamed ${ }^{1, *}$, Monir Rehan², Shaheen Dalia ${ }^{3}$, Eladl Ahmed ${ }^{4}$ \\ Physiology department ${ }^{1}$, Biochemistry department ${ }^{2}$, Biochemistry department ${ }^{3}$, \\ Pathology department ${ }^{4}$ Faculty of Medicine, Mansoura University
}

Received: 11 July 2019

Accepted: 26 August 2019

Available online: 1 Jan 2020

\begin{abstract}
Hydrogen sulfide has been recently studied as a potential treatment for many cardiovascular disorders. Here, we describe its role in I/R- induced cardiac hypertrophy and arrhythmia model. Thirty six male Sprague Dawley rats were used in this study. Rats were randomly divided into 6 groups, G 1(n = 6/group): control negative: received saline, $\mathrm{G} 2, \mathrm{I} / \mathrm{R}$ rats, $(\mathrm{I} / \mathrm{R}, \mathrm{n}=6)$, after right nephrectomy, the rats were subjected to left kidney ischemia for 45 minutes followed by reperfusion:,G3, I/R rats in which rats were treated by $\mathrm{NaHS}$, the donor of $\mathrm{H}_{2} \mathrm{~S}(5 \mathrm{mg} / \mathrm{kg} /$ day $\times 14$ days) intraperitoneal,G4, I/R rats in which rats were treated by the blocker of $\mathrm{H}_{2} \mathrm{~S}$ aminooxyacetic acid $(10 \mathrm{mg} / \mathrm{kg} / \mathrm{day} \times 14$ days) intraperitoneal,G5, I/R rats in which rats were treated by converting enzyme inhibitor (Captopril) $(50 \mathrm{mg} / \mathrm{Kg} /$ day $\times 14$ days $)$ and, $\mathrm{G} 6, \mathrm{I} / \mathrm{R}$ rats in which rats were treated by NaHS and $\mathrm{K}_{\mathrm{ATP}}$ channel blocker (Glibenclamide) $(20 \mathrm{mg} / \mathrm{kg} /$ day $\times 14$ days). NaHS led to a highly significant decrease in the duration of ventricular action potential indicated by QTc. Furthermore, it decreased, significantly, both of mean blood pressure and plasma renin activity. Moreover, $\mathrm{H}_{2} \mathrm{~S}$ donor and converting enzyme inhibition increased the expression of CX-43. While ( $/ / \mathrm{R}+\mathrm{NaHS}+\mathrm{K}_{\mathrm{ATP}}$ channel block) led to a non-significant decreased in the duration of QTc interval. This showed that hydrogen sulfide generation has a potential therapeutic role in IR-induced cardiac hypertrophy and arrhythmia via amelioration of $\mathrm{CX}-43$ expression and opening of $\mathrm{K}_{\mathrm{ATP}}$ channels.
\end{abstract}

Keywords

- Hydrogen sulfide

*Corresponding author: Mohamed Adel, Department of Medical Physiology, Faculty of Medicine, Mansoura University, Egypt. Email: madel7744@yahoo.com/madel@mans.edu.eg ; Tel.: +201222218973 


\section{Introduction}

Cardiac hypertrophy represents a fundamental adaptive response of heart to the increased working demand (1) and has been hypothesized to be a response to biomechanical stress, such as pressure overloading and volume overloading in which heart initiates a process leading to the increase in cardiac mass and augmentation of the pump function (2). The hypothesis is supported by in-vivo experiments where the expansion of myofibrillar apparatus of cardiomyocytes and collagen deposition occurring during hypertrophy results from the interaction between mechanical stresses (i.e. external load) and the release of autocrine/paracrine growth factors, such as angiotensin II and insulin-like growth factor-I (IGF-I) (3,4). Although initially beneficial, sustained cardiac hypertrophy may incur a temporal deterioration leading to the impairment of the cardiac functions $(5,6)$. Cardiac hypertrophy, usually, is considered as an effective compensation mechanism, can maintain or even increase cardiac output. However, in the long term, persistent hypertrophy will ultimately result in cardiac dilatation, decreased ejection fraction, and subsequent heart failure (7).

Cardiac gap junctions play a major role in impulse propagation and have also been implicated in arrhythmogenesis. Connexin43 (CX-43) is the principal connexin in the mammalian ventricles and has been proven to have a close association with arrhythmia $(8,9)$. In fact, reduced expression of myocardial CX-43 protein, has been related to abnormalities in the intercellular propagation of the electrical impulses (10) and, in turn, to mechanical deficiencies observed in heart under hypertensive conditions (11) and in hypertrophied or congestive heart failure (12). However, only a few "in vitro" studies have postulated an involvement of this protein in the development of the immediate adaptive hypertrophic response. Early modulators of heart hypertrophy, such as cAMP and angiotensin II (10), as well as, 1 to 4 hours of pulsatile stretches $(13,14)$ have been shown to induce a rapid up-regulation of CX-43 protein associated with a marked increase in impulse propagation velocity. CX-43 quantity in failing myocardium was reduced by $40 \%$ in every transmural muscle layer compared with control, corresponding well with previous reports of a $50 \%$ reduction of CX-43 protein expression and $40 \%$ reduction of CX-43 mRNA in congestive heart failure (15, 16, and 17). However, the significance of CX-43 expression patterns on electrophysiological function and arrhythmogenesis was poorly understood.

Hydrogen sulfide (H2S) is an endogenously produced gaseous molecule with important roles in cellular signaling. This chemical has been implicated in 
regulation of inflammatory responses, cardiovascular functions, renal functioning and gastrointestinal system (18, 19). Furthermore, H2S has been shown to exert a potent cytoprotective abilities against tissue injury, including organ fibroses such as myocardial and renal fibrosis $(20,21)$. Cystathionine-synthase and cystathioninelyase use L-cysteine as a substrate to produce H2S. The discovery of cystathionine-lyase in the rat heart, as well as, identification of $\mathrm{H} 2 \mathrm{~S}$ as an important modulator is a breakthrough in the investigation of the role of $\mathrm{H} 2 \mathrm{~S}$ in heart functions. Increasing evidence has demonstrated that disturbed $\mathrm{H} 2 \mathrm{~S}$ production is relevant to heart diseases. Plasma $\mathrm{H} 2 \mathrm{~S}$ levels were significantly lowered in coronary heart disease patients compared with that in angiographically normal subjects $(22,23)$. The endogenous production of $\mathrm{H} 2 \mathrm{~S}$ is significantly reduced in many heart diseases, including myocardial ischemia and myocardial infarction- induced heart failure (24). These findings imply that cardiac diseases may impair the endogenous synthesis of $\mathrm{H} 2 \mathrm{~S}$, which may further exacerbate the disease state. Meanwhile, these findings are clear evidence which support the involvement of endogenous $\mathrm{H} 2 \mathrm{~S}$ in maintaining basal physiological functions of heart. However, the role of $\mathrm{H} 2 \mathrm{~S}$ in the pathogenesis of cardiac hypertrophy, and the relationship between $\mathrm{H} 2 \mathrm{~S}$ and the dysregulation of cardiac rhythm remains unclear.

We set out therefore to: (i) test the hypothesis that a unilateral renal I/R model can induce cardiac hypertrophy and arrhythmogenesis; and, if confirmed, (ii) assess whether the decrease in CX-43 expression is involved in renal $\mathrm{I} / \mathrm{R}$-induced cardiac hypertrophy and arrhythmia. (iii) investigate the possible protective effects of $\mathrm{H} 2 \mathrm{~S}$ against cardiac hypertrophy and arrhythmia in I/R- induced cardiac hypertrophy and arrhythmia model.

\section{Materials and Methods}

\subsection{Experimental Animals}

Adult male Sprague Dawley rats $(n=36$; weight, $250 \pm 40$ gram) were obtained from the medical experimental research center (MERC) of faculty of medicine, Mansoura university. Our Local Committee of Animal Care and Use approved I/R protocol (Code number: R.19.04.490). The animals had free access to food and water and were housed in individual cages with a 12-hour light-dark cycle. The animals were adapted to these conditions for at least one week before being used in the experiments and general conditions were monitored throughout the study.

\subsection{Study groups}

Rats were randomly divided into 6 groups $G 1$ ( $n=6 /$ group): control negative: in which rats received saline (Sal group= Sham-operated control) and were subjected 
to surgical opening and closing in the abdominal region with gentle external manipulation of the vascular pedicle without occlusion. G2, control positive I/R rats, (I/R, $n=6 /$ group), $G 3$ ( $n=6 /$ group), I/R rats: in which rats were treated by NaHS, the donor of $\mathrm{H} 2 \mathrm{~S}$, administered intraperitoneally with $\mathrm{NaHS}$ saline solution (NaHS as a $\mathrm{H} 2 \mathrm{~S}$ donor $5 \mathrm{mg} / \mathrm{kg} /$ day $\times 14$ days intraperitoneal), The first dose of NaHS was administered 24 hours after model was successfully established (25), G4 ( $\mathrm{n}=6$ /group), I/R rats in which rats were treated by the blocker of H2S, aminooxyacetic acid (AOAA) $10 \mathrm{mg} / \mathrm{kg} /$ day $\times 14$ days intraperitoneal purchased from Sigma-Aldrich (25). G5 (n $=6 /$ group $), \quad \mathrm{I} / \mathrm{R}$ rats in which rats were treated by angiotensin converting enzyme inhibitor (ACEI) (Captopril) $50 \mathrm{mg} / \mathrm{Kg} /$ day $\times 14$ days, given with gastric gavage (26). And, G6 ( $n=6 /$ group), I/R rats in which rats were treated by NaHS, the donor of $\mathrm{H} 2 \mathrm{~S}$ and the ATP-sensitive potassium (KATP) channel blocker (Glibenclamide) $(20 \mathrm{mg} / \mathrm{kg} /$ day $\times 14$ days, given with gastric gavage) (26).

\subsection{Ischemia reperfusion $(I / R)$ surgery}

After right nephrectomy through median abdominal incision to make the solitary kidney model, left renal artery was separated from renal pedicle. In I/R group, the left renal artery was blocked for 45 minutes before reperfusion. After recovery, rats were maintained with food and water ad libitum.
Once surgery was done to the animals, a group of them $(n=6)$ was selected at random to receive sodium hydrogen sulfide (NaHS), an exogenous donor of $\mathrm{H} 2 \mathrm{~S}$, was purchased from Sigma-Aldrich (Merck KGaA, Darmstadt, Germany). Another group $(n=6)$ was selected at random to receive blocker of $\mathrm{H} 2 \mathrm{~S}$ aminooxyacetic acid (AOAA). Another group $(\mathrm{n}=6)$ was selected at random to receive ACEI (Captopril). Another group $(\mathrm{n}=6)$ was selected at random to receive $\mathrm{NaHS}$ and ATP-sensitive potassium (KATP) channel blocker (Glibenclamide). Arterial blood pressure was measured daily with a noninvasive pressure meter (LE 5001). Administration of drugs was stopped one day before the end of the experiment.

2.4. Collection of cardiac samples and determination of heart to body weight $(H W / B W)$ ratios

Fifteen days after ischemia reperfusion surgery, the animals were anesthetized with pentobarbital $(0.6 \mathrm{ml} / \mathrm{kg})$ and the blood collected by heart puncture and allowed to clot for 30 minutes. Serum was separated by centrifugation at $2500 \mathrm{rpm}$ for 15 minutes and used for biochemical estimations. After that, rats were sacrificed by cervical dislocation and the chest of terminated animal was cut open quickly and the heart was immediately removed and washed thoroughly with ice-cold $0.9 \%$ sodium chloride solution (Saline) and dried with 
filter paper before weighing to measure heart weight (HW) to find out $\mathrm{HW} / \mathrm{BW}$ ratio. After removal of the atria and large vessels of the base, the left ventricle was transversely sectioned into 3 parts of $3 \mathrm{~mm}$ thickness between apex and base; one part was fixed in $10 \%$ formaldehyde, which was left for H\& E and Masson's trichrome staining. The other parts were used to assess biochemical parameters.

\subsection{Histopathological examination of}

cardiac tissue by Hematoxylin /Eosin $(H \& E)$ and Masson trichrome staining

Portions of isolated hearts were preserved in $10 \%$ formalin for 24 hours. Specimens were cut in section of $3-5 \mu \mathrm{m}$ in thickness to be stained with (H\&E) stain in order to examine the morphological changes. Additionally, ventricular sections were stained with Masson's trichrome to examine extracellular matrix (ECM) deposition. The grading system used for assessment of parameters was [-: Absence of change; +: $0-30 \%$ area shows changes (Mild); + +: 30-60\% area shows changes (Moderate); +++ + $60-100 \%$ area shows focal changes (Severe focal); ++++ : 60 $100 \%$ area shows diffuse changes (Severe diffuse)] (27).

2.6. Quantitative real-time PCR for connexin-43 (CX-43) mRNA assay

RNA isolation and reverse transcription were performed. The obtained single-chain DNA was used for real-time
PCR. Amplification was performed in $10 \mu \mathrm{l}$ of SYBR Green PCR Master Mix containing 30 pmol.1-1 of each primer. For amplification of GJP43 gene and beta-actin (Housekeeping gene for normalization was not reported to be changed in $I / R$ ), gene fragments of the following primers were used to determine CX43-mRNA level: GJP43, sense 5'-TCC TTG GTG TCT CTC GCT TT-3', antisense 5'-GAG CAG CCA TTG AAG TAG GC-3'; and beta-actin, sense 5'-TCA TCA CTA TCG GCA ATG AGC-3', antisense 5'-GGC CAG GAT AGA GCC ACC A-3'. Sample volume was adjusted to $20 \mu \mathrm{l}$ with deionized water. Amplification was performed as previously described (28). Cycle threshold (CT) was defined as the number of cycles required for the fluorescence signal to exceed the detection threshold. We calculated the expression of the target gene relative to the housekeeping gene as the difference between CT values of the two genes.

\subsection{Electrocardiography (ECG)}

Basal ECG (lead II) of each rat was recoded for 30 seconds, fifteen days after ischemia reperfusion, by using computerized data acquisition system (BIOPAC Student Lab 3.7.6). The rats were anaesthetized by Ketamine ( 0.2 $\mathrm{mg} / \mathrm{g})$ and xylazine $(10 \mathrm{mg} / \mathrm{kg})$ injected intraperitoneally. The following ECG variables were analyzed: QRS duration, a corrected QT interval (QTc), and RR interval. QTc was calculated using Bazett's formula. The formula is based on 
dividing $\mathrm{QT}$ interval by the square root of RR-interval in seconds. A corrected QT interval (QTc) that takes into account changes in heart rate is often used as a more objective parameter of depolarization and repolarization of ventricles.

$$
\text { QTc }=\frac{Q T}{\sqrt{\frac{R R}{f}}}
$$

Where $f$ is the normalization factor according to the basal $\mathrm{RR}$ duration in rats that is $150 \mathrm{~ms}$. As $\mathrm{QT}$ interval is inversely correlated to heart rate, correction of QT interval is important to interpret QT interval independent of heart rate. The results were expressed in tables, and data were analyzed statistically.

2.8. Assay of lipid peroxidation marker malondialdhyde (MDA) and antioxidant reduced glutathione (GSH) activity in cardiac tissues

About 50 -100 mg of cardiac tissues were homogenized in 1-2 $\mathrm{ml}$ cold buffer $(50 \mathrm{mM}$ potassium phosphate, $\mathrm{PH} 7.5,1 \mathrm{mM}$ EDTA) using mortar and pestle then centrifuged at 4,000 rpm for 15 minutes at $4{ }^{\circ} \mathrm{C}$. The supernatant was kept at $-20^{\circ} \mathrm{C}$ until used for analysis of oxidants and antioxidants. MDA and GSH in the supernatant of cardiac homogenates were measured using a colorimetric method according to the manufacturer's instructions (BioDiagnostics, Dokki, Giza, Egypt).
2.9. ELISA for determination of cardiac marker creatine kinase- $M B$ isoenzyme (CK$M B)$

It is a sandwich enzyme immunoassay for in vitro quantitative measurement of $\mathrm{CK}$ MB (Cardiac marker) in rat serum. It was purchased from Sigma- Aldrich co. Egypt.

\subsection{Arterial blood pressure measurement}

Arterial blood pressure was measured by pressure meter (LE 5001). This pressure meter is a microprocessor based instrument designed to perform non-invasive blood pressure determination from rats' tails.

\subsection{Determination of plasma renin activity} (PRA)

PRA indicates the overall activity of renin angiotensin aldosterone system. Furthermore to generate angiotensin I (A-I), PRA measurements are valid to monitor the renin angiotensin aldosterone system during pharmacological interventions. PRA-RIA kits were used for the quantitative determination of PRA by radioimmunoessay of the generated A-I $(29,30)$.

\subsection{Assessment of renal functions}

\section{Determination of blood urea nitrogen}

Urea in the sample was hydrolyzed enzymatically into ammonia and carbon dioxide. Ammonia ions formed react with salicylate and hypochlorite $(\mathrm{NaClO})$ in the presence of the catalyst nitroprusside, to form green indophenols. The intensity of the color formed is proportional to the urea concentration in the sample (31). 
Determination of serum creatinine

The collected blood samples were allowed to clot for 30 minutes, serum was separated by centrifugation at $2500 \mathrm{rpm}$ for 15 minutes and stored at $-20^{\circ} \mathrm{C}$ for analysis of serum creatinine. Serum creatinine level was estimated according to the manufacturer's instructions (Bio-Diagnostic Dokki, Giza, Egypt) (32).

\subsection{Statistical data and analysis}

Data are presented as means +/- standard deviation (SD) *: $(\mathrm{P}<0.05)$, **: $(\mathrm{P}<0.01)$, ***: $(\mathrm{P}<0.001)$ by using SPSS (SPSS, Sigma Plot Software, Inc, Chicago, IL) program statistical package for social science version 17. One-way analyses of variance (ANOVA) were used to compare each molecular variable between control negative (Saline), control positive (I/R), I/R $+\mathrm{H}_{2} \mathrm{~S}$ donor NaHS, I/R $+\mathrm{H} 2 \mathrm{~S}$ blocker aminooxyacetic acid (AOAA), I/R + ACEI (Captopril) and I/R + NaHS + $\mathrm{K}_{\mathrm{ATP}}$ channel blocker (Glibenclamide) groups. When a significant interaction was detected, posthoc t-tests were used to compare the two groups at different time points. Pearson correlation analyses were used to study the

Table (1): Body weight $(\mathrm{g})$, heart weight $(\mathrm{g})$ and relative heart weight ( $\mathrm{g} / \mathrm{g}$ body weight) (HW/BW) in different studied groups

\begin{tabular}{|c|c|c|c|c|c|c|}
\hline & $\begin{array}{l}\text { Control } \\
\text { Sal. }\end{array}$ & $\mathbf{I} / \mathbf{R}$ & $\begin{array}{l}\mathbf{I} / \mathbf{R}+\mathbf{H}_{2} \mathrm{~S} \\
\text { donor } \\
(\mathrm{NaHS})\end{array}$ & $\begin{array}{c}\mathbf{I} / \mathbf{R}+\mathbf{H}_{2} \mathrm{~S} \\
\text { blocker } \\
\text { (AOAA) }\end{array}$ & $\begin{array}{l}\text { I/R + } \\
\text { ACEI }\end{array}$ & $\begin{array}{c}\mathbf{I} / \mathbf{R}+\mathrm{NaHS}+\mathbf{K}_{\mathrm{ATP}} \\
\text { channel blocker } \\
\text { Glibenclamide }\end{array}$ \\
\hline Body weight (g) & $250 \pm 21.5$ & $240 \pm 29.5$ & $252 \pm 27.5$ & $233 \pm 21$ & $230 \pm 27$ & $225 \pm 27$ \\
\hline Heart weight (g) & $0.649 \pm 0.1$ & $1.13 \pm 0.1 \#$ & $0.75 \pm 0.2 \# *$ & $0.93 \pm 0.2 \#$ & $0.8 \pm 0.2 \# *$ & $0.7 \pm 0.1 \# *$ \\
\hline HW/BW & 0.002 & $0.004 \#$ & $0.002 *$ & $0.003 \# *$ & $0.003 \# *$ & $0.003 \# *$ \\
\hline
\end{tabular}

Test used: ANOVA followed by posthoctukey for multiple comparisons. Values are expressed as means \pm S.D $(n=6)$. \#: $(\mathrm{P}<0.05)$ significant vs control group $(\mathrm{G} 1)$. *: $(\mathrm{P}<0.05)$ significant vs I/R group (G2). Sal.: saline. relationships between relative heart weights, mean blood pressure, plasma renin activity, serum creatinine, blood urea nitrogen and corrected QT interval in I/R group. Results were considered significant when $(\mathrm{P}<0.05)$.

\section{Results}

\subsection{I/R-induced cardiac hypertrophy}

As shown in table (1), heart weight and its relative weight increased significantly in $\mathrm{I} / \mathrm{R}$ group $(\mathrm{P}<0.05)$ in proportional to control sal group. While heart weight and its relative weight decreased significantly in $(\mathrm{I} / \mathrm{R}+\mathrm{H} 2 \mathrm{~S}$ donor NaHS) group in proportional to I/R group. Moreover, heart weight decreased, non-significantly in I/R + $\mathrm{H}_{2} \mathrm{~S}$ blocker aminooxyacetic acid (AOAA) group in proportional to $\mathrm{I} / \mathrm{R}$ group. In addition, heart weight and its relative weight decreased significantly in ( $\mathrm{I} / \mathrm{R}+\mathrm{ACEI})$ group. Also, heart weight and its relative weight decreased significantly $(\mathrm{P}<0.05)$ in $(\mathrm{I} / \mathrm{R}+\mathrm{NaHS}+$ glibenclamide $)$ group in proportional to I/R group. group $(\mathrm{P}<0.05)$ in proportional to $\mathrm{I} / \mathrm{R}$ 
3.2. Effects of $I / R, H 2 S$, angiotensin converting enzyme inhibitor (Captopril) and $K_{A T P}$ channel blocker (Glibenclamide) on mean blood pressure (MBP), plasma renin activity (PRA), cardiac MDA, cardiac GSH and creatine kinase- MB isoenzyme (CK$M B)$

As shown in table (2), I/R led to a significant increase in MBP after 15 days of reperfusion in proportional to control group. Also, I/R led to a significant increase $(\mathrm{P}<$ 0.05) in PRA in proportional to control group. I/R led to a significant increase in MDA $(\mathrm{P}<0.05)$ in proportional to control group. I/R led to a significant decrease in GSH $(\mathrm{P}<0.05)$ in proportional to control group and a non-significant increase in $\mathrm{CK}$ $\mathrm{MB}$, in proportional to control group. In $\mathrm{I} / \mathrm{R}+\mathrm{H}_{2} \mathrm{~S}$ donor group, $\mathrm{H}_{2} \mathrm{~S}$ donor NaHS led to a significant decrease in MBP in proportional to I/R group. Also, NaHS led to a significant decrease $(\mathrm{P}<0.05)$ in PRA in proportional to IR group. NaHS led to a significant decrease in MDA in proportional to $\mathrm{I} / \mathrm{R}$ group. NaHS led to a significant increase $(\mathrm{P}<0.05)$ in $\mathrm{GSH}$ in proportional to $\mathrm{I} / \mathrm{R}$ group and a non-significant decrease in CK-MB in proportional to $/ / R$ group. In $I / R$ $+\mathrm{H}_{2} \mathrm{~S}$ blocker aminooxyacetic acid (AOAA) group, AOAA led to a non-significant decrease in MBP in proportional to $\mathrm{I} / \mathrm{R}$ group. Also, AOAA led to a significant decrease in PRA in proportional to $I / R$ group. AOAA led to a significant decrease in MDA in proportional to $I / R$ group. AOAA led to a non-significant increase in GSH in proportional to I/R group and a nonsignificant increase in $\mathrm{CK}-\mathrm{MB}$ in proportional to $\mathrm{I} / \mathrm{R}$ group. In (I/R + ACEI captopril) group, captopril led to a significant decrease in MBP in proportional to IR group. Also, captopril led to a nonsignificant increase in PRA in proportional to IR group and a significant decrease in MDA in proportional to IR group. Moreover, captopril led to a significant increase in GSH in proportional to IR group and a non-significant decrease in CK-MB in proportional to IR group. In (I/R + NaHS + glibenclamide) group, there is a significant decrease in MBP $(\mathrm{P}<0.05)$ in proportional to IR group. Also, there is a significant decrease in PRA in proportional to IR group $(\mathrm{P}<0.05)$. Also, there is a significant decrease in MDA in proportional to IR group $(\mathrm{P}<0.05)$. Moreover, glibenclamide led to a significant increase in GSH in proportional to IR group and a nonsignificant decrease in CK-MB in proportional to IR group. 
Table (2): Effects of $\mathrm{I} / \mathrm{R}, \mathrm{H}_{2} \mathrm{~S}$ donor $\mathrm{NaHS}, \mathrm{H}_{2} \mathrm{~S}$ blocker aminooxyacetic acid (AOAA), angiotensin converting enzyme inhibitor (Captopril) and $\mathrm{K}_{\mathrm{ATP}}$ channel blocker (Glibenclamide) on mean blood pressure (MBP), plasma renin activity (PRA), cardiac MDA, cardiac GSH and creatine kinase- MB isoenzyme.

\begin{tabular}{cccccc}
$\begin{array}{c}\text { Control } \\
\text { Sal. }\end{array}$ & I/R & $\begin{array}{c}\mathbf{I} / \mathbf{R}+\mathbf{H}_{2} \mathbf{S} \\
\text { donor }(\mathbf{N a H S})\end{array}$ & $\begin{array}{c}\mathbf{I} / \mathbf{R}+\mathbf{H}_{2} \mathbf{S} \\
\text { blocker } \\
\text { (AOAA) }\end{array}$ & $\begin{array}{c}\mathbf{I} / \mathbf{R}+\text { ACEI } \\
\text { (Captopril) }\end{array}$ & $\begin{array}{c}\mathbf{I} / \mathbf{R}+\text { NaHS } \\
+\mathbf{K}_{\text {ATP }} \text { channel } \\
\text { blocker } \\
\text { (Glibenclamide) }\end{array}$ \\
\hline $92 \pm 2.5$ & $156 \pm 19.5^{*}$ & $133 \pm 17.5^{* \#}$ & $154 \pm 15.5^{*}$ & $106 \pm 19.5^{*} \#$ & $131 \pm 15.5^{*} \#$
\end{tabular}

\begin{tabular}{lcccccc}
\hline MBP (mmHg) & $92 \pm 2.5$ & $156 \pm 19.5^{*}$ & $133 \pm 17.5^{* \#}$ & $154 \pm 15.5^{*}$ & $106 \pm 19.5^{* \#}$ & $131 \pm 15.5^{* \#}$ \\
\hline PRA (ng/ ml./ h.) & $4.6 \pm 1.3$ & $29 \pm 4.5^{*}$ & $17 \pm 3.5^{*} \#$ & $14 \pm 4.5^{*} \#$ & $31 \pm 3.1^{*}$ & $15 \pm 4.9^{*} \#$ \\
\hline $\begin{array}{l}\text { MDA (nmol/g. } \\
\text { cardiac tissue) }\end{array}$ & $26.7 \pm 3.77$ & $59 \pm 4.58^{*}$ & $28 \pm 3.63 \#$ & $42 \pm 5.83^{*} \#$ & $31 \pm 3.63^{* \#}$ & $47 \pm 3.41^{* \#}$ \\
\hline $\begin{array}{l}\text { GSH (nmol/g. } \\
\text { cardiac tissue) }\end{array}$ & $7.96 \pm 1.3$ & $3.55 \pm 1.5^{*}$ & $21 \pm 2.31^{* \#}$ & $6 \pm 2.17$ & $19 \pm 2.34^{* \#}$ & $18 \pm 3.11^{* \#}$ \\
\hline $\begin{array}{l}\text { CK-MB } \\
\text { (IU/L) }\end{array}$ & $19.66 \pm$ & $22.41 \pm 4.53$ & $20 . \pm 6.42$ & $24.32 \pm 4.83$ & $21.5 \pm 5.71$ & $21.66 \pm 2.91$ \\
\hline
\end{tabular}

Test used: ANOVA followed by posthoctukey for multiple comparisons. Values are expressed as means \pm S.D. $(\mathrm{n}=6)$. *: $(\mathrm{P}<0.05)$ significant vs control $(\mathrm{Sal})$ group. \#: $(\mathrm{P}<0.05)$ significant vs I/R group. Sal: saline.

\subsection{Cardiac electrical profile "In vivo"}

ECG record showed that QT interval was $(108 \pm 17)(\mathrm{m} . \mathrm{sec}$.) in I/R group with a significant increase in proportional to control (Sal) group $(88 \pm 25) \quad(m . \quad$ sec.) (Figure 1 A \& 1 B). In (I/R $+\mathrm{H}_{2} \mathrm{~S}$ donor NaHS) group, QT was $(88 \pm 15)$ (m. sec.) with a significant decrease in proportional to $\mathrm{I} / \mathrm{R}$ group (Figure 1C). In (I/R + ACEI) group, QT was $(84 \pm 17)$ (m. sec.) (Figure 1 E) with a significant decrease in proportional to $\mathrm{I} / \mathrm{R}$ group. In $(\mathrm{I} / \mathrm{R}+\mathrm{H} 2 \mathrm{~S}$ donor + Glibenclamide) group, QT was (100 \pm 15 ) (m. sec.) (Figure 1F) with a nonsignificant decrease in proportional to $I / R$ group. ECG record showed that there was an increase in ventrcilular action potential duration (Indicated by prolonged QTc) in I/R group, it increased significantly from $(179 \pm 18) \quad(\mathrm{m} . \mathrm{sec})$ to $(220 \pm 11)$ (m. sec.) (Figure 1B). While NaHS, captopril and $\mathrm{K}_{\text {ATP }}$ channel blocker (Glibenclamide) decreased it. QTc decreased from $(220 \pm 11)$ (m. sec.) to $(179 \pm 16)(\mathrm{m} . \mathrm{sec}$.) $(\mathrm{P}<0.001)$, $(171 \pm 5)(\mathrm{m} . \mathrm{sec}).(\mathrm{P}<0.001)$ and $(204 \pm 34)$ (m. sec.) respectively (Figure 1 C, 1 E \&1 F). 

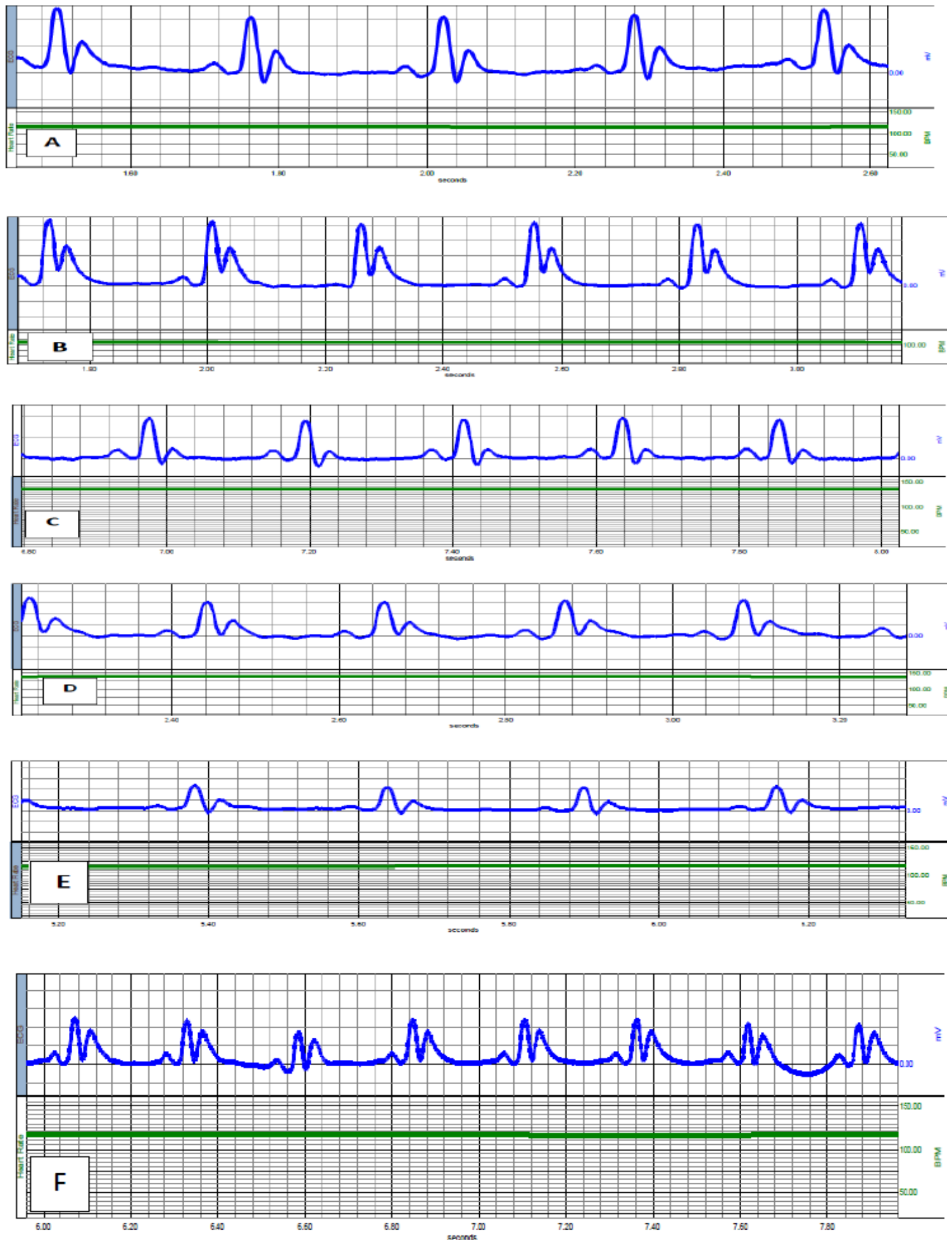

Figure (1): Representative traces of electrocardiograms. A) ECG of sal group. B) ECG of I/R group. C) ECG of $\mathrm{I} / \mathrm{R}+\mathrm{H}_{2} \mathrm{~S}$ donor group NaHS. D) ECG of $/ / \mathrm{R}+\mathrm{H}_{2} \mathrm{~S}$ blocker aminooxyacetic acid (AOAA). E) ECG of $\mathrm{I} / \mathrm{R}+$ angiotensin converting enzyme inhibitor (Captopril). F) ECG of I/R + NaHS + $\mathrm{K}_{\mathrm{ATP}}$ channel blocker (Glibenclamide). 
3.4. Assessment of kidney functions

As shown in table (3), I/R increased both of serum creatinine level and blood urea nitrogen (BUN) level significantly $(\mathrm{P}<$ 0.05 ) in proportional to control. While $\mathrm{H}_{2} \mathrm{~S}$ donor (NaHS) decreased both of serum creatinine level and BUN level significantly $(\mathrm{P}<0.05)$ in proportional to $\mathrm{I} / \mathrm{R}$ group. In addition, $\mathrm{H}_{2} \mathrm{~S}$ blocker aminooxyacetic acid
(AOAA) increased both of serum creatinine level and BUN non-significantly in proportional to $\mathrm{I} / \mathrm{R}$ group. While ACEI (Captopril) decreased both of serum creatinine level and BUN significantly $(\mathrm{P}<$ 0.05 ) in proportional to I/R group. Also, $\mathrm{H}_{2} \mathrm{~S}$ and glibenclamide decreased both of serum creatinine level and BUN significantly $(\mathrm{P}<0.05)$ in proportional to $\mathrm{I} / \mathrm{R}$ group.

Table (3): Effects of I/R, $\mathrm{H}_{2} \mathrm{~S}$ donor NaHS, $\mathrm{H}_{2} \mathrm{~S}$ blocker aminooxyacetic acid (AOAA), angiotensin converting enzyme inhibitor (Captopril) and $\mathrm{K}_{\mathrm{ATP}}$ channel blocker (Glibenclamide) on serum creatinine and blood urea nitrogen $(\mathrm{BUN})$ level.

\begin{tabular}{|c|c|c|c|c|c|c|}
\hline & $\begin{array}{l}\text { Control } \\
\text { Sal. }\end{array}$ & $\mathbf{I} / \mathbf{R}$ & $\begin{array}{c}\mathbf{I} / \mathbf{R}+\mathbf{H}_{2} \mathrm{~S} \\
\text { donor } \\
(\mathrm{NaHS})\end{array}$ & $\begin{array}{c}\mathbf{I} / \mathbf{R}+\mathbf{H}_{2} \mathrm{~S} \\
\text { blocker } \\
(\text { AOAA) }\end{array}$ & $\begin{array}{c}\text { I/R + } \\
\text { ACEI } \\
\text { Captopril }\end{array}$ & $\begin{array}{c}\text { I/R + NaHS + } \\
\text { K }_{\text {ATP }} \text { channel } \\
\text { blocker } \\
\text { Glibenclamide }\end{array}$ \\
\hline $\begin{array}{c}\text { Serum } \\
\text { creatinine } \\
(\mathbf{m g} \%)\end{array}$ & $\begin{array}{c}0.58 \pm \\
0.08\end{array}$ & $1.29 \pm 0.3 \#$ & $\begin{array}{c}0.9 \\
\pm 0.13^{* \#}\end{array}$ & $\begin{array}{c}1.33 \\
\pm 0.17 \#\end{array}$ & $\begin{array}{c}0.83 \\
\pm 0.23^{* \#}\end{array}$ & $0.93 \pm 0.3 * \#$ \\
\hline $\begin{array}{c}\text { BUN) (mg } \\
\%)\end{array}$ & $\begin{array}{c}17.17 \pm \\
6.1 \\
\end{array}$ & $\begin{array}{c}42.76 \pm \\
5.8 \#\end{array}$ & $\begin{array}{c}33.43 \pm \\
5.6^{* \#}\end{array}$ & $43.88 \pm 5 . \#$ & $\begin{array}{c}21.66 \pm \\
7 . * \# \\
\end{array}$ & $20.56 \pm 5 . * \#$ \\
\hline
\end{tabular}

Test used: ANOVA followed by posthoctukey for multiple comparisons. \#: $(\mathrm{P}<0.05)$ vs control. *: $(\mathrm{P}<0.05)$ vs I/R. $\mathrm{n}=(6)$ in all groups. Sal.: saline.

3.5. Effects of I/R, $\mathrm{H}_{2} \mathrm{~S}$, ACEI (Captopril) and $K_{A T P}$ channel blocker (Glibenclamide) on morphology of cardiac muscle fibers

Ventricular slices from sal group (Figure 2A\& Table 4) showed a normal appearance for cardiac muscle fibers, while those obtained from I/R group (Figure 2B\& Table 4) showed degeneration of myocardial muscle with hypertrophy of ventricular muscle as compared to sal. group with increased cardiomyocytes width (++++) $(H \& E \times 100)$. The number of abnormal fibers was reduced in the cardiac tissues obtained from $\mathrm{I} / \mathrm{R}+\mathrm{H}_{2} \mathrm{~S}$ donor NaHS, it showed mild hypertrophy of the ventricular muscle, cardiomyocytes width (+) (Figure 2C\& Table 4). I/R + ACEI (Captopril) showed mild hypertrophy of the ventricular muscle, myocytes width (+) (Figure 2E\& Table 4). Also, $\mathrm{I} / \mathrm{R}+\mathrm{NaHS}+\mathrm{K}_{\text {ATP }}$ channel blocker (Glibenclamide) group showed mild hypertrophy of the ventricular muscle, cardiomyocytes width (+) (Figure 2F\& Table 4). 

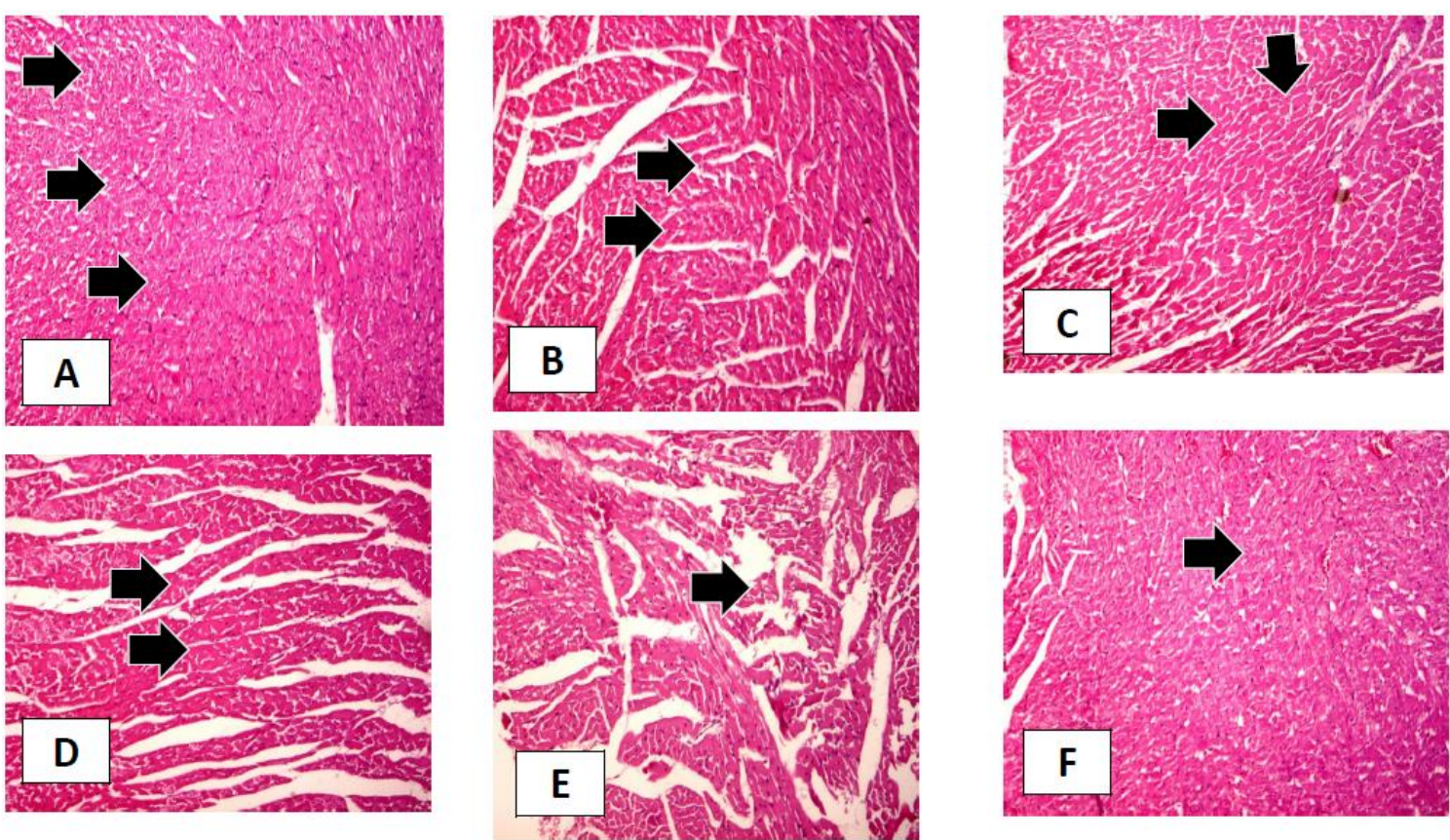

Figure (2): graphical representation of cardiomyocytes obtained using hematoxylin and eosin stained ventricular slices A) H\&E staining of sal group $(n=6)$ : showed a normal appearance for cardiac muscle fibers B) $H \& E$ staining of $I / R$ group $(n=6)$ : hypertrophy and increased cardiomyocytes width (Arrow head) C) $\mathrm{H} \& \mathrm{E}$ staining of $\mathrm{I} / \mathrm{R}+\mathrm{H}_{2} \mathrm{~S} \quad(\mathrm{n}=6)$ : decreased cardiomyocytes width (Arrow head) $D$ ) $\mathrm{H} \& \mathrm{E}$ staining of $\mathrm{I} / \mathrm{R}+\mathrm{H} 2 \mathrm{~S}$ blocker group aminooxyacetic acid (AOAA) $(\mathrm{n}=6)$ : decreased cardiomyocytes width E) $H \& E$ staining of $I / R+$ angiotensin converting enzyme inhibitor (Captopril) group ( $n=6$ ): decreased cardiomyocytes width F) H\&E staining of $\mathrm{I} / \mathrm{R}+\mathrm{NaHS}+$ Glibenclamide $(\mathrm{n}=6)$ : decreased cardiomyocytes width (Arrow head).

\section{6. $\mathrm{H}_{2} \mathrm{~S}$ donor (NaHS), ACEI (Captopril)} and $K_{A T P}$ channel blocker (Glibenclamide) administration attenuated $I / R$-induced heart fibrosis

Ventricular slices from sal group (Figure 3A\& Table 4) showed a normal appearance for cardiac muscle fibers with no evidence of fibrosis, while those obtained from I/R group (Figure 3B \& Table 4) showed marked fibrosis, fibrosis $(+++)$, between the hypertrophied fibers (Masson trichrome $\times 100$ ). The number of abnormal fibers was significantly reduced in cardiac tissues obtained from I/R + NaHS, ACEI (Captopril) and glibenclamide groups which showed mild fibrosis (Figure 3C, 3E \& 3F \& Table 4). 

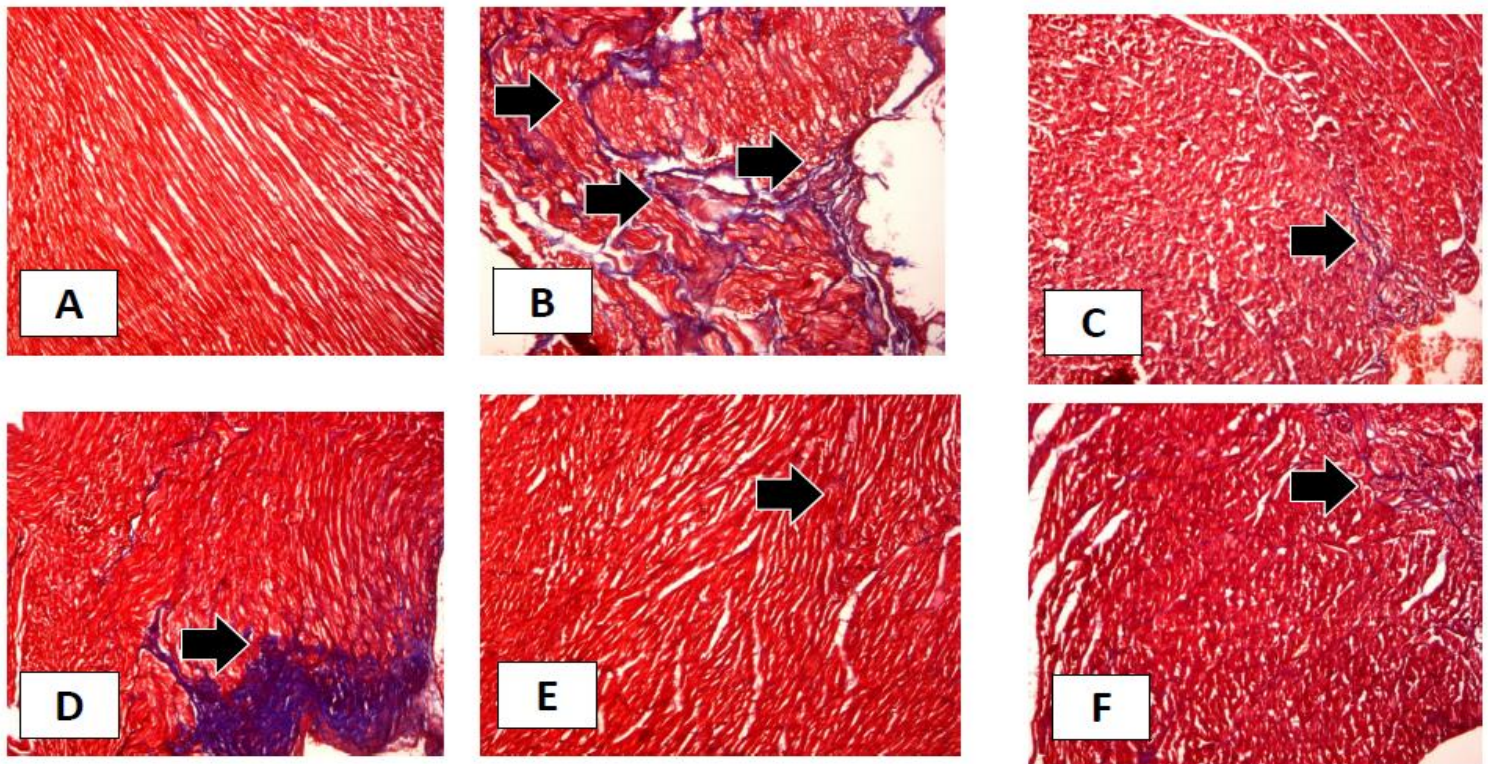

Figure (3): graphical representation of ventricular slices stained with Masson trichrome stain. A) Masson trichrome staining of sal. group $(n=6)$ : showed a normal appearance for cardiac muscle fibers with no evidence of fibrosis (Masson trichrome $\times 100)$ B) Masson trichrome staining of I/R group $(n=6)$ : Masson's trichrome stain shows marked fibrous connective tissue proliferation, fibrosis $(+++)$, between the hypertrophied fibers with increased cardiomyocytes width (Arrow head) (Masson trichrome $\times 100$ ) C) Masson trichrome staining of $\mathrm{I} / \mathrm{R}+\mathrm{H}_{2} \mathrm{~S} \quad(\mathrm{n}=6)$ : Masson's trichrome stain showed mild degree of fibrosis, fibrosis (+), and decreased cardiomyocytes width (Arrow head) (Masson trichrome $\times 100$ ) D) Masson trichrome staining of $\mathrm{I} / \mathrm{R}+\mathrm{H}_{2} \mathrm{~S}$ blocker aminooxyacetic acid (AOAA) $(\mathrm{n}=6)$ : decreased cardiomyocytes width and fibrosis (++) (Masson trichrome $\times 100)$ E) Masson trichrome staining of $\mathrm{I} / \mathrm{R}+$ angiotensin converting enzyme inhibitor (Captopril) group $(\mathrm{n}=6)$ : decreased cardiomyocytes width (Arrow head) and fibrosis (+) F) Masson trichrome staining of I/R + NaHS + Glibenclamide ( $\mathrm{n}=6)$ : Masson's trichrome stain shows mild fibrosis, fibrosis $(+$ ), (Arrow head) and decreased cardiomyocytes width (Masson trichrome $\times$ 100).

Table (4): Semi quantitative scoring of myocardial lesions within different studied groups

\begin{tabular}{ccccccc}
\hline & $\begin{array}{c}\text { Control } \\
\text { Sal. }\end{array}$ & $\mathbf{I} / \mathbf{R}$ & $\begin{array}{c}\text { I/R }+ \\
\mathbf{H}_{2} \mathbf{S} \\
\text { donor } \\
\text { (NaHS) }\end{array}$ & $\begin{array}{c}\text { I/R + H2S } \\
\text { blocker } \\
\text { (AOAA) }\end{array}$ & $\begin{array}{c}\text { I/R + ACEI } \\
\text { Captopril }\end{array}$ & $\begin{array}{c}\text { I/R + NaHS + } \\
\text { KaTP channel } \\
\text { blocker } \\
\text { Glibenclamide }\end{array}$ \\
\hline $\begin{array}{c}\text { Normal } \\
\text { fibers } \\
\text { histology }\end{array}$ & +++ & + & ++ & ++ & + & + \\
\hline $\begin{array}{c}\text { Myocardial } \\
\text { degeneration }\end{array}$ & - & +++ & + & ++ & + & + \\
\hline Myolysis & - & +++ & + & ++ & + & + \\
\hline Fibrosis & - & +++ & + & ++ & + & + \\
\hline $\begin{array}{c}\text { Myocyte } \\
\text { hypertrophy }\end{array}$ & - & +++ & + & ++ & + & + \\
\hline
\end{tabular}

(-) indicates no detectable lesions; (+) indicates mild lesions; (++) indicates moderate lesions;

$(+++)$ indicates severe focal lesions; (++++) indicates severe diffuse lesions. 
3.7. Effects of $I / R, I / R+H 2 S$ donor (NaHS), $I / R+$ angiotensin converting enzyme inhibitor (Captopril) and $I / R+N a H S+$ $K_{A T P}$ channel blocker (Glibenclamide) on CX-43 expression in cardiac tissues

As shown in figure (4), cardiac tissues from sal group showed a normal expression of CX-43, while those obtained from I/R group showed a significant decrease in its expression in proportional to control sal
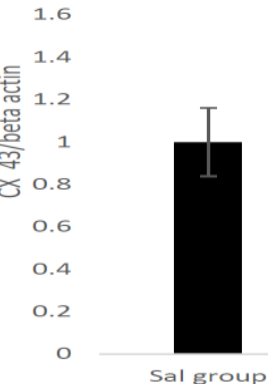

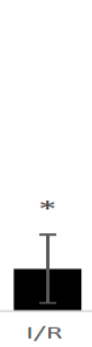

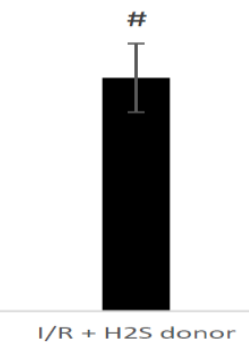

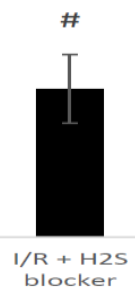

group. Moreover, the expression of CX- 43 increased significantly in the cardiac tissues obtained from $\mathrm{H}_{2} \mathrm{~S}$ donor (NaHS) $+\mathrm{I} / \mathrm{R}$ in proportional to $\mathrm{I} / \mathrm{R}$ group. In addition, angiotensin converting enzyme inhibitor (Captopril) $+\mathrm{I} / \mathrm{R}$, as well as, $\left(\mathrm{NaHS}+\mathrm{K}_{\mathrm{ATP}}\right.$ channel blocker Glibenclamide $+\mathrm{I} / \mathrm{R})$ increased its expression significantly in proportional to I/R group.

Figure (4): Expression levels of CX-43 in the myocardia of all studied groups. Data are expressed as mean \pm SD, test used: One way ANOVA, followed by post-hoc tukey. (Normalized by beta actin, products of RT-PCR for CX-43). P: significance <0.05. *: significant as compared with sal. group. \#: significant as compared with I/R group. Sal.: saline.

3.8. Correlations between relative heart weights $(H W / B W)$, mean blood pressure $(M B P)$, plasma renin activity (PRA), serum creatinine, blood urea nitrogen (BUN) and QTc in I/R group

I/R showed significant positive correlations between HW/BW, MBP, PRA, serum creatinine, BUN and corrected QT (QTc) (Table 5).

Table (5): Correlations between relative heart weights (HW/BW), mean blood pressure (MBP), plasma renin activity (PRA), serum creatinine, blood urea nitrogen (BUN) and QTc in I/R group

\begin{tabular}{|c|c|c|c|c|c|c|}
\hline Parameters & HW/BW & MBP & PRA & Creatinine & BUN & QTe \\
\hline \multirow[t]{2}{*}{ HW/BW } & $\mathrm{r}$ & 0.710 & 0.624 & 0.849 & 0.859 & 0.901 \\
\hline & $\mathrm{p}$ & 0.000 & 0.001 & 0.000 & 0.000 & 0.000 \\
\hline \multirow[t]{2}{*}{ MBP } & $\mathrm{r}$ & & 0.82 & 0.706 & 0.516 & 0.630 \\
\hline & $\mathrm{p}$ & & 0.000 & 0.000 & 0.010 & 0.001 \\
\hline \multirow[t]{2}{*}{ PRA } & $r$ & & & 0.381 & 0.998 & 0.375 \\
\hline & $\mathrm{p}$ & & & 0.066 & 0.000 & 0.071 \\
\hline \multirow{2}{*}{$\begin{array}{c}\text { Serum } \\
\text { creatinine }\end{array}$} & $\mathrm{r}$ & & & & 0.997 & 0.958 \\
\hline & $\mathrm{p}$ & & & & 0.000 & 0.000 \\
\hline \multirow[t]{2}{*}{ BUN } & $\mathrm{r}$ & & & & & 0.299 \\
\hline & $\mathrm{p}$ & & & & & 0.155 \\
\hline
\end{tabular}

$\mathrm{HW} / \mathrm{BW}=$ heart weight/ body weight, $\mathrm{MBP}$ = mean blood pressure, $\mathrm{PRA}=$ plasma renin activity, $\mathrm{BUN}=$ blood urea nitrogen, QTc =corrected QT, QTc indicates QT interval divided by the square root of RRinterval in seconds. r: Pearson's correlation coefficient. $\mathrm{P}$ : probability. $(\mathrm{P}<0.05)$ is considered significant. $(\mathrm{P}<0.001)$ is considered highly significant. 


\section{Discussion}

The correlation of cardiac dysrhythmias symptomatology with changes in gap junctions in cardiac muscle had formed the bases for IR-induced cardiac hypertrophy and arrhythmias. Since then, the general hypothesis of therapeutic effect of hydrogen sulfide generation in cardiac diseases was expanded to arrhythmias and cardiac hypertrophy where it ameliorates CX-43. The main findings in the present study are: (a) I/R arrhythmias are associated with decreased expression of CX-43 protein (b) I/R increased duration of QTc interval while $\mathrm{H} 2 \mathrm{~S}$ donor (NaHS) normalized it (c) the cardioprotective effect of $\mathrm{H} 2 \mathrm{~S}$ against arrhythmias, depends on both of KATP channels opening and amelioration of CX43 expression

To test the hypothesis that the primary kidney acute I/R injury can culminate with a cardiorenal syndrome with several degrees of cardiac structural and electrical dysfunctions $(33,34)$, we examined morphological, molecular and functional parameters that would reflect an increase in cardiac mass after I/R. Heart weight/body weight $(\mathrm{HW} / \mathrm{BW})$ ratios are useful indirect indicators of cardiac hypertrophy, and these parameters increased after 15 days of reperfusion. Other parameters related to cardiac hypertrophy were also measured, including: cardiomyocyte width, CX-43 expression, cardiac MDA, cardiac GSH and
CK-MB. The data strongly suggest cardiac hypertrophy developed by 15 days of renal reperfusion. Cardiac electrical profiles are also in line with the morpho-structural alterations described above i.e. longer QTc.

In the present study, a significant elevation of heart weight in $\mathrm{I} / \mathrm{R}$ group, indicating that $\mathrm{I} / \mathrm{R}$ resulted in cardiac hypertrophy. HW/BW ratio increased significantly in $\mathrm{I} / \mathrm{R}$ group. In the present study, I/R is able to modulate cardiac tissue structure, differently regulating collagen content in distinct sections of the heart tissue in rats subject to renal $\mathrm{I} / \mathrm{R}$. Myocardial hypertrophy could be explained by the inflammatory mediators which migrate through blood stream to affect heart and induce oxidative stress in cardiac tissue and vessels which culminate with cardiomyocytes hypertrophy and elevated blood pressure. This happened after an intense inflammatory response in the left kidney reperfusion with its impact in cardiac and vascular tissues. This was confirmed by increasing the levels of cardiac MDA, CK$\mathrm{MB}$, arterial blood pressure and decreasing cardiac GSH.

In the present study, NaHS reduced cardiac hypertrophy. In agreement with the previous findings that $\mathrm{H} 2 \mathrm{~S}$ could improve cardiac functions and reduce myocardial hypertrophy by reducing NOX4 expression and ROS production in mitochondria (33, $34,35$, and 36$)$. $\mathrm{H} 2 \mathrm{~S}$ has been reported as a 
strong antioxidant and widely proposed to protect the cardiac system through its antioxidant role. The robust antioxidant actions of $\mathrm{H} 2 \mathrm{~S}$ are associated with direct scavenging of ROS and increased expressions and functions of antioxidant enzymes. In addition, H2S therapy mitigates pathological left ventricular remodeling and reduces myocardial hypertrophy, oxidative stress and apoptosis (37\&38). Endogenous $\mathrm{H} 2 \mathrm{~S}$ in rats could maintain basal arterial blood pressure balance, attenuate elevated arterial blood pressure, and lessen vascular structural remodeling in hypertensive rats (39, 40, 41, and 42).

Here, NaHS led to a highly significant decrease in the duration of ventricular action potential indicated by QTc. This is in agreement with the previous finding that reperfusion with NaHS after ischemia attenuated arrhythmias in the isolated Langendorff-perfused heart and improved cardiac function during $\mathrm{I} / \mathrm{R}$ (13). Also, preconditioning with $100 \mu \mathrm{M} \quad \mathrm{NaHS}$ attenuated arrhythmias in the isolated heart during $\mathrm{I} / \mathrm{R}$ and these effects may be mediated by protein kinase $\mathrm{C}$ and sarcolemmal KATP channels (13). These effects were blocked by KATP channel blocker (Glibenclamide), indicating that the cardioprotective effect of $\mathrm{H} 2 \mathrm{~S}$ against arrhythmias during reperfusion, at least partially, depends on opening of KATP channels.
Intercellular CX-43 channels are essential for direct communication between cardiomyocytes, ensuring action potential and molecular signal propagation resulting in synchronized heart function. Gap junctional intercellular communication (GJIC) is important in physiological processes such as homeostasis, growth regulation, coordination of cellular responses to stimuli, and apoptosis. In addition, cardiac gap junctions play a major role in impulse propagation. In contrast, aberrant connexin expression and defective GJIC are involved in many diseases such as cardiac arrhythmia and neurodegeneration. In the present study, myocardial CX-43 expression was lesser in $\mathrm{I} / \mathrm{R}$ versus control sal rats. This deterioration of CX-43 level affects the intercellular communication which may be behind the prolongation of the QRS and QTc. Here, H2S ameliorated the expression of CX-43 in cardiac tissue, which indicated that endogenous H2S may play an important role in regulating heart functions and arrhythmia. This is in agreement with the previous finding that the lowered $\mathrm{H} 2 \mathrm{~S}$ production may cause overstimulation of the $\beta$-adrenergic function which was closely linked with the incidence of ventricular arrhythmias (42, 43, and 44). Exogenous application of $\mathrm{H} 2 \mathrm{~S}$ negatively modulated $\beta$ adrenergic function by inhibiting adenylyl cyclase activity and, finally, protected heart against cardiac arrhythmias. 
The longer QRS and QT seen after 15 days of reperfusion are consistent with previous studies which examined the association of electrocardiographic changes with cardiac hypertrophy $(45,46)$. The longer QT interval has special relevance that, together with the "in vivo" electrophysiology alterations, is considered a predictor of arrhythmias (47, 48). The most consistent electrical abnormality that has been described in association with cardiac hypertrophy is extending action potential duration. In rats, among the different $\mathrm{K}^{+}$currents, the transient outward current, a major repolarizing current, is the major determinant of action potential duration (49). In rats, previous studies demonstrated specific alterations in the transient outward current (48). In experimental cardiac hypertrophy, a number of electrophysiological abnormalities have been reported, including myocardial areas of both short and long action potential duration. Such heterogeneous repolarization occurs mainly in fibrotic areas $(50,51)$.

In the present study, converting enzyme inhibition normalized QTc interval in renal I/R-induced arrhythmia. This could be explained by its inhibitory effect on cardiac angiotensin-converting enzyme activity. In agreement with the previous finding that ACEI reverses left ventricle hypertrophy by reducing the load and by a direct trophic effect on cardiomyocyte proliferation
$(52,53,54 \& 55)$, through its lowering effect on angiotensin II formation and its inhibition of bradykinin degradation.

Here, in the present study, the histological findings showed marked myocardial necrosis associated with nuclear lysis and marked increase in cardiomyocyte width, together with large patches of strong fibrous tissue reactivity between the hypertrophied fibers in the heart sections of I/R rats. These alterations could be highly attributed to I/Rinduced oxidative stress and inflammation that leads to DNA damage and apoptosis (56). Cardiac fibrosis occurs as a consequence of inflammation and cell injury as confirmed by various studies $(57 \& 58)$. However, in the present study, NaHS improved cardiac architecture, and reduced cardiac fibrosis. So, H2S is able to protect the heart against $\mathrm{I} / \mathrm{R}$-induced cellular injury and fibrosis probably through its ability to reduce I/R- induced inflammation and apoptosis together with improving CX-43 expression.

In addition, since the preservation of cardiac-renal axis integrity is vital in all physiological scenarios, it could be hypothesized that prevention or attenuation of renal lesions after I/R injury contributes to prevent I/R-induced cardiac hypertrophy. This hypothesis is supported by several studies showing that knockout mice seem to be protected against renal metabolic and cardiovascular injuries (59). Also, in the 
present study, NaHS decreased serum creatinine and BUN level significantly $(\mathrm{P}<0.05)$ in proportional to $\mathrm{I} / \mathrm{R}$ group. We assessed serum creatinine and BUN level to answer the question of whether there is a correlation between renoprotective effect of $\mathrm{H} 2 \mathrm{~S}$ and its antiarrhythmic effect? Hydrogen sulfide protects against cardiac hypertrophy and arrhythmia in rats model of renal ischemia/reperfusion via its cardioprotective, as well as, its renoprotective effect.

\section{Conclusion}

$\mathrm{I} / \mathrm{R}$ involves the damage of the myocardium through several mechanisms, namely fibrosis and inflammatory induced hypertrophy of cardiomyocytes. The decreased CX-43 expression is a key for the development of arrhythmias in renal I/R induced cardiac hypertrophy. Hydrogen sulfide protects against renal I/R -induced cardiac hypertrophy and arrhythmia through amelioration of CX-43 expression and opening of $\mathrm{K}_{\mathrm{ATP}}$ channels. Based on these findings, $\mathrm{H}_{2} \mathrm{~S}$ replacement therapy may be a crucial cardioprotective and antiarrhythmic intervention for those patients whose plasma $\mathrm{H}_{2} \mathrm{~S}$ level is reduced. Clinical trials may also be considered to validate the results in humans, following further pre-clinical studies.

\section{Acknowledgements}

The authors acknowledge Medical Experimental Research Center MERC of Mansoura University for the significant contribution to the experimental part of the study.

\section{Author Contributions}

Mohamed Adel: the idea, the induction of I/R model, ECG record, biochemical analysis, data analysis and paper writing.

Dalia Shaheen: biochemical analysis and paper writing Rehan Monir: biochemical analysis and paper writing. Ahmed El Adl: histopathological examination

Conflicts of Interest: The author declares no conflict of interest

\section{References}

1. Chien K.R. (1999). Stress pathways and heart failure. Cell 98, 555-558.

2. Anversa P. and Capasso J.M. (1991). Cardiac hypertrophy and ventricular remodeling. Lab. Invest. 64, 441-445.

3. Modesti P.A., Vanni S., Bertolozzi I., Cecioni I., Polidori G., Paniccia R., Bandinelli B., Perna A.M., Liguori P., Boddi M., Galanti G. and Neri Serneri G.G. (2000). Early sequences of cardiac adaptations and growth factor formation in pressure- and volume- 
overload hypertrophy. Am. J. Physiol. (Heart Circ. Physiol.) 279, H976-H985.

4. Molkentin J.D. (2000). Calcineurin and beyond. Cardiac hypertrophic signaling. Circ. Res. 87, 731-738.

5. Minamisawa S., Hoshijima M., Chu G., Ward C.A., Frank K., Gu Y., Martone M.E., Wang Y., Ross J., Kranias E.G., Giles W.R. and Chien K.R. (1999). Chronic phospholambansarcoplasmic reticulum calcium ATPase interaction is the critical calcium cycling defect in dilated cardiomyopathy. Cell 99, 313-322.

6. Yeager M. (1998). Structure of cardiac gap-junction intercellular channels. J. Struct. Biol. 121, 231-245.

7. C. Indolfi, E. di Lorenzo, C. Perrino et al., "Hydroxymethylglutaryl coenzyme a reductase inhibitor simvastatin prevents cardiac hypertrophy induced by pressure overload and inhibits p21ras activation," Circulation, vol. 106, no. 16, pp. 2118-2124, 2002.

8. W. Roell, T. Lewalter, P. Sasse et al. "Engraftment of connexin 43expressing cells prevents post-infarct arrhythmia," Nature, vol. 450, no. 7171, pp. 819-824, 2007.

9. J. L. Huang, D. M. Wang, J. B. Zheng, X. S. Huang, and H. Jin. "Hydrogen sulfide attenuates cardiac hypertrophy and fibrosis induced by abdominal aortic coarctation in rats," Molecular Medicine Reports, vol. 5, no. 4, pp. 923-928, 2012.

10. Beardslee M.A., Lerner D.L., Tadros P.N., Laing J.G. Beyer E.C., Yamada K.A., Kebler A.G., Schulssler R.B. and Saffitz J.E. (2000). Dephosphorilation and intracellular redistribution of ventricular connexin 43 and electrical uncoupling induced by ischemia. Circ. Res. 87, 656-662.

11. Emdad L., Uzzaman M., Takagishi Y., Honjo H., Uchida T., Severs N.J., Kodama I. and Murata Y. (2001). Gap junction remodeling in hypertrophied left ventricles of aorticbanded rats: prevention by angiotensin II type receptor blockade. J. Mol. Cell Cardiol. 33, 219-231.

12. Severs N.J., Rothery S., Dupont E., Coppen S.R., Yeh H.I., Ko Y.S. Matsushita T., Kaba R. and Halliday D. (2001). Immunocytochemical analysis of connexin expression in the healthy and diseased cardiovascular system. Microsc. Res. Tech. 52, 301-322.

13. Zhuang J., Yamada K.A., Saffitz J.E. and Klèber A.G. (2000). Pulsatile stretch remodels cell-to-cell communication in cultured myocytes. Circ. Res. 87, 316-322.

14. Dupont E, Matsushita T, Kaba RA, Vozzi C, Coppen SR, Khan N, Kaprielian R, Yacoub MH, and 
Severs NJ. Altered connexin expression in human congestive heart failure. J Mol Cell Cardiol 33: 359$371,2001$.

15. Peters NS, Green CR, Poole-Wilson PA, and Severs NJ. Reduced content of connexin 43 gap junctions in ventricular myocardium from hypertrophied and ischemic human hearts. Circulation 88: 864-875, 1993.

16. Wang $\mathbf{X}$ and Gerdes AM. Chronic pressure overload cardiac hypertrophy and failure in guinea pigs. III. Intercalated disc remodeling. J Mol Cell Cardiol 31: 333-343, 1999.

17. Sawyer DB, Siwik DA, Xiao L, et al. Role of oxidative stress in myocardial hypertrophy and failure. $J \mathrm{Mol}$ Cell Cardiol. 2002;34:379-388.

18. Saavedra WF, Paolocci N, St John ME, et al. Imbalance between xanthine oxidase and nitric oxide synthase signaling pathways underlies mechanoenergetic uncoupling in the failing heart. Circ Res. 2002;90:297304.

19. Bendall JK, Cave AC, Heymes C, et al. Pivotal role of a gp91(phox)containing NADPH oxidase in angiotensin II-induced cardiac hypertrophy in mice. Circulation. 2002;105:293-296.

20. Li JM, Gall NP, Grieve DJ, et al. Activation of NADPH oxidase during progression of cardiac hypertrophy to failure. Hypertension. 2002; 40:477484.

21. Xiao L, Pimentel DR, Wang J, et al. Role of reactive oxygen species and $\mathrm{NAD}(\mathrm{P}) \mathrm{H}$ oxidase in alpha 1adrenoceptor signaling in adult rat cardiac myocytes. Am J Physiol Cell Physiol. 2002; 282:C926-C934.

22. H.-L. Jiang, H.-C. Wu, Z.-L. Li, B. Geng, and C.-S. Tang, "Changes of the new gaseous transmitter $\mathrm{H}_{2} \mathrm{~S}$ in patients with coronary heart disease," Academic Journal of the First Medical College of PLA, vol. 25, no. 8, pp. 951-954, 2005.

23. D. J. Polhemus, J. W. Calvert, J. Butler, and D. J. Lefer. "The cardioprotective actions of hydrogen sulfide in acute myocardial infarction and heart failure," Scientifica, vol. 2014, Article ID 768607, 8 pages, 2014.

24. Y. H. Liu, M. Lu, L. F. Hu, P. T. H. Wong, G. D. Webb, and J. S. Bian. "Hydrogen sulfide in the mammalian cardiovascular system," Antioxidants \& Redox Signaling, vol. 17, no. 1, pp. 141-185, 2012.

25. Zhao DA, Liu J, Huang $\mathbf{Q}$ and Han ZM: Change in plasma $\mathrm{H} 2 \mathrm{~S}$ level and therapeutic effect of $\mathrm{H} 2 \mathrm{~S}$ supplementation in tubulointerstitial fibrosis among rats with unilateral ureteral obstruction. Zhongguo Dang Dai Er Ke Za Zhi 15: 903-908, 2013. 
26. Pompermayer K, Amaral FA, Fagundes CT, Vieira AT, Cunha FQ, Teixeira MM, Souza DG. Effects of the treatment with glibenclamide, an ATP-sensitive potassium channel blocker, on intestinal ischemia and reperfusion injury. Eur J Pharmacol. 2007;556(1-3):215-222.

27. Badole, S.L. L-glutamine supplementation prevents the development of experimental diabetic cardiomyopathy in streptozotocinnicotinamide induced diabetic rats. PLoS One, 2014. 9(3): p. e92697.

28. Anna, Z., et al. Heart-protective effect of n-3 PUFA demonstrated in a rat model of diabetic cardiomyopathy. Mol Cell Biochem, 2014. 389(1-2): p. 21927.

29. Guan, S.; Fox, J.; Mitchell, K.D.; Navar, L.G. Angiotensin and angiotensin converting enzyme tissue levels in two-kidney, one clip hypertensive rats. Hypertension (Dallas Tex. 1979) 1992, 20, 763-767.

30. Murakami, P., Eggena P., Barrett J.D., and Sambhi MP. Heterogeneity of renin substrate released from hepatocytes and in brain extracts. Life Sci 34:385-392, 2004.

31. Kaplan A. Clin chem. St Louis, Toronto, Princeton: The C.V. Mosby Co.; 1984. pp. 1257-1260; 437 and 418.
32. Murray RL. Clin chem. St Louis, Toronto, Princeton: The C.V. Mosby Co.; 1984. pp. 1261-1266; 418.

33. McCullough PA, Kellum JA, Haase M, Müller C, Damman K, Murray PT, et al. Pathophysiology of the cardiorenal syndromes: executive summary from the Eleventh Consensus Conference of the Acute Dialysis Quality Initiative (ADQI). Blood Purif. 2014; 37: 2-13.

34. Haber, E., Koerner, T., page, L.B., Kliman, B., and purnode, A.: (1992) J. Clin. Endocr. Metab.29, 1349-1355.

35. F. Lu, J. Xing, X. Zhang et al. "Exogenous hydrogen sulfide prevents cardiomyocyte apoptosis from cardiac hypertrophy induced by isoproterenol," Molecular and Cellular Biochemistry, vol. 381, no. 1-2, pp. 41-50, 2013.

36. C. K. Nicholson, J. P. Lambert, J. D. Molkentin, J. Sadoshima, and J. W. Calvert. "Thioredoxin 1 is essential for sodium sulfide-mediated cardioprotection in the setting of heart failure," Arteriosclerosis, Thrombosis, and Vascular Biology, vol. 33, no. 4, pp. 744-751, 2013.

37. P. K. Mishra, N. Tyagi, U. Sen, S. Givvimani, and S. C. Tyagi. " $\mathrm{H}_{2} \mathrm{~S}$ ameliorates oxidative and proteolytic stresses and protects the heart against adverse remodeling in chronic heart failure," American Journal of 
Physiology-Heart and Circulatory

Physiology, vol. 298, no. 2, pp. H451-

H456, 2010.

38. Yan H, Du J, Tang C. The possible role of hydrogen sulfide on the pathogenesis of spontaneous hypertension in rats. Biochem Biophys Res Commun 2004;313:22-7.

39. Geng B, Yang J, Qi Y, Zhao J, Pang Y, Du J, et al. H2S generated by heart in rat and its effects on cardiac function. Biochem Biophys Res Commun 2004;313:362-8.

40. Yin J, Tu C, Zhao J, Ou D, Chen G, Liu Y, et al. Exogenous hydrogen sulfide protects against global cerebral ischemia/reperfusion injury via its anti-oxidative, anti-inflammatory and anti-apoptotic effects in rats. Brain Res 2013;1491:188-96.

41. Calvert JW, Elston M, Nicholson CK, Gundewar S, Jha S, Elrod JW, et al. Genetic and pharmacologic hydrogen sulfide therapy attenuates ischemia-induced heart failure in mice. Circulation 2010;122:11-9.

42. Y.-H. Liu, M. Lu, Z.-Z. Xie et al. "Hydrogen sulfide prevents heart failure development via inhibition of renin release from mast cells in isoproterenol-treated rats," Antioxidants \& Redox Signaling, vol. 20, no. 5, pp. 759-769, 2014.
43. J. Huang, D. Wang, J. Zheng, X. Huang, and H. Jin. "Hydrogen sulfide attenuates cardiac hypertrophy and fibrosis induced by abdominal aortic coarctation in rats," Molecular Medicine Reports, vol. 5, no. 4, pp. 923-928, 2012.

44. F. Yang, Z. Liu, Y. Wang, Z. Li, H. Yu, and Q. Wang. "Hydrogen sulfide endothelin-induced myocardial hypertrophy in rats and the mechanism involved," Cell Biochemistry and Biophysics, vol. 70, no. 3, pp. 16831686, 2014.

45. Cheng Y, Wan X, McElfresh TA, Chen X, Gresham KS, Rosenbaum DS, et al. Impaired contractile function due to decreased cardiac myosin binding protein $\mathrm{C}$ content in the sarcomere. Am J Physiol Heart Circ Physiol. 2013; 305: H52-65.

46. Levin ER, Gardner DG, Samson WK. Natriuretic peptides. N Engl J Med. 1998; 339: 321-8.

47. Tang T, Lai NC, Wright AT, Gao MH, Lee P, Guo T, et al. Adenylyl cyclase 6 deletion increases mortality during sustained $\beta$-adrenergic receptor stimulation. J Mol Cell Cardiol. 2013; 60: 60-7.

48. De Bruyne MC, Hoes AW, Kors JA, Hofman A, vam Bemmel JH, Grobbee DE. Prolonged QT interval predicts cardiac and all-cause mortality 
in the elderly. Eur Heart J. 1999; 20:

278-84.

49. Benitah JP, Gomez AM, Bailly P, Da Ponte JP, Berson G, Delgado C, Lorente P. Heterogeneity of the early outward current in ventricular cells isolated from normal and hypertrophied rat ventricles. $J$ Physiol (Lond). 1993;469:118-138.

50. Weber KT, Janicki JS, Shroff SG, Pick R, Chen RM, Bashey RI. Collagen remodeling of the pressureoverload, hypertrophied non-human primate myocardium. Circ Res. 1988;62:757-765.

51. James TN. Normal and abnormal consequences of apoptosis in the human heart. Circulation. 1994;90:556 -573.

52. Diez J, Panizo A, Hernandez M, Vega F, Sola I, Fortuno MA, Pardo J. Cardiomyocyte apoptosis and cardiac angiotensin-converting enzyme in spontaneously hypertensive rats. Hypertension. 1997;30:1029-1034.

53. Chevalier B, Heudes D, Heymes C, Bassett A, Dakhli T, Bansart Y, Jouquey S, Hamon G, Bruneval P, Swynghedauw B, et al. Trandolapril decreases prevalence of ventricular ectopic activity in middle-aged SHR. Circulation. 1995;92:1947-1953.

54. Aasen, T.; Mesnil, M.; Naus, C.C.; Lampe, P.D.; Laird, D.W. Gap junctions and cancer: Communicating for 50 years. Nat. Rev. Cancer 2016, $16,775-788$.

55. Srinivas, M.; Verselis, V.K.;White, T.W. Human diseases associated with connexin mutations. Biochim. Biophys. Acta Biomembr. 2018, 1860, 192-201.

56. Williams, L.J., B.G. Nye, and A.R. Wende. Diabetes-Related Cardiac Dysfunction. Endocrinol Metab (Seoul), 2017. 32(2): p. 171-179.

57. Russo, I. and N.G. Frangogiannis. Diabetes-associated cardiac fibrosis: Cellular effectors, molecular mechanisms and therapeutic opportunities. J Mol Cell Cardiol, 2016. 90: p. 84-93.

58. Frati, G., et al. An overview of the inflammatory signalling mechanisms in the myocardium underlying the development of diabetic cardiomyopathy. Cardiovasc Res, 2017. 113(4): p. 378-388.

59. Wu H, Steenstra R, de Boer ECS, Zhao CY, Ma J, van der Stelt JM, et al. Preconditioning with recombinant high-mobility group box 1 protein protects the kidney against ischemiareperfusion injury in mice. Kidney Int. 2014; 85: 824-32. 